Raymond J. Martineau MD, Claude P. Tousignant MD, Donald R. Miller MD, Kathryn A. Hull RN

\title{
Alfentanil controls the haemodynamic response during rapid- sequence induction of anaesthesia
}

\begin{abstract}
Laryngoscopy and tracheal intubation often cause hypertension and tachycardia, which may be exaggerated during rapid-sequence induction of anaesthesia. A placebo-controlled, doubleblind study was conducted in 60 patients to determine doseresponse and effects on myocardial performance of alfentanil when used to attenuate this cardiovascular response. Patients were divided into four groups to receive a pre-induction bolus from a coded syringe, which contained either normal saline (PLAC), alfentanil $30 \mu \mathrm{g} \cdot \mathrm{kg}^{-1}$ (ALF 30), alfentanil $45 \mu \mathrm{g} \cdot$ $\mathrm{kg}^{-3}$ (ALF 45) or alfentanil $60 \mu \mathrm{g} \cdot \mathrm{kg}^{-1}$ (ALF 60). Anaesthesia was induced in rapid sequence with thiopentone $4.0 \mathrm{mg} \cdot \mathrm{kg}^{-1}$ and succinylcholine $1.5 \mathrm{mg} \cdot \mathrm{kg}^{-1}$, and the trachea was intubated $60 \mathrm{sec}$ later. Increases in heart rate $(21 \pm 10 \mathrm{bpm})$, mean arterial pressure $(28 \pm 13 \mathrm{mmHg})$, and systemic vascular resistance index $\left(1420 \pm 780\right.$ dynes $\left.\cdot \mathrm{sec}^{-1} \cdot \mathrm{cm}^{-5}\right)$ were observed in response to intubation with PLAC but in none of the $3 A L F$ groups $(P<0.05)$. However, heart rate and mean arterial pressure decreased significantly in both the ALF 45 and $A L F 60$ groups $(P<0.05)$, whereas $A L F 30$ resulted in no change in these variables over time. Cardiac index, stroke volume index, and ejection fraction tended to decrease in all four groups, but none of these variables was different at corresponding time when comparing the ALF groups with PLAC. We conclude that
\end{abstract}

\section{Key words}

ANAESTHETICS, INTRAVENOUS : alfentanil; COMPLICATIONS: hypertension, tachycardia; INTUBATION: complications, rapid sequence.

From the Department of Anaesthesia, Ottawa General Hospital and the University of Ottawa, Ottawa, Ontario.

Supported by a research grant from Janssen Pharmaccutica (Canada).

Presented in part at the Annual Meeting of The American Society of Anesthesiologists, Ncw Orleans, Louisiana, October, 1989

Address correspondence to: Dr. Donald R. Miller, Department of Anaesthesia, Ottawa General Hospital, 501 Smyth Road, Ottawa, Ontario K1H 8L6.
ALF $30 \mu \mathrm{g} \cdot \mathrm{kg}^{-1}$ administered prior to rapid-sequence induction of anaesthesia, effectively attenuates the hypertensive, tachycardic response to intubation, without altering global indices of cardiac function. Alfentanil in doses of 45 and 60 $\mu \mathrm{g} \cdot \mathrm{kg}^{-1}$ result in transient but significant decreases in $H R$ and MAP with this anaesthetic technique

La laryngoscopie et l' intubation endotrachéale souvent amènent l' hypertension et la tachycardie qui peuvent être exagérées lors de l'induction rapide de l'anesthésie. Une étude contrôlée avec un placébo et à double insu a été conduite chez 60 patients afin de déterminer la courbe de dose-réponse et les effets sur la performance myocardique avec l'alfentanil lorsqu'utilisé afin d'atténuer cette réponse cardiovasculaire. Les patients furent divisés en quatre groupes afin de recevoir un bolus en pré-induction d'une seringue codée qui contenait soit du salin physiologique (PLAC), soit de l'alfentanil $30 \mu \mathrm{g} \cdot \mathrm{kg}^{-1}$ (ALF 30), soit de l'alfentanil $45 \mu \mathrm{g} \cdot \mathrm{kg}^{-1}$ (ALF 45) ou de l'alfentanil $60 \mu \mathrm{g}$. $\mathrm{kg}^{-1}$ (ALF 60). L'anesthésie, avec une séquence rapide d'induction, fut obtenue avec du thiopentone $4.0 \mathrm{mg} \cdot \mathrm{kg}^{-1}$ et de la succinylcholine $1,5 \mathrm{mg} \cdot \mathrm{kg}^{-1}$ après quoi la trachée fut intubée 60 secondes plus tard. L'augmentation de la fréquence cardiaque $(21 \pm 10 \mathrm{bpm})$, la pression artérielle moyenne $(28 \pm 13 \mathrm{mmHg})$, et l'index de résistance vasculaire systémique (1420 \pm 780 dynes $\cdot \mathrm{sec}^{-1} \cdot \mathrm{cm}^{-5} I-r \cdot \mathrm{cm}^{-5}$ ) fut observé en réponse à l'intubation avec la PLAC mais dans aucun des autres trois groupes $A L F(P<0,05)$. Cependant, la fréquence cardiaque et la pression artérielle moyenne ont diminué significativement dans les deux groupes ALF 45 et $A L F 60(P<0,05)$ alors que dans le groupe $A L F$ 30, aucun changement ne fut observé durant le temps de l'étude. L'index cardiaque, le volume d'éjection indexé et la fraction d'éjection démontraient une tendance à la diminution dans les quatre groupes mais aucune de ces variables n'était différente au temps correspondant lorsque comparée avec les groupes ALF et PLAC. On conclut que l'ALF $30 \mu \mathrm{g} \cdot \mathrm{kg}^{-1}$ administré avant la séquence rapide d'induction de l'anesthésie a atténué efficacement l'hypertension et la tachycardie en réponse d̀ l' intubation sans altérer les indices globaux de la fonction cardiaque. L'alfentanil à des doses de 45 et 
$60 \mu \mathrm{g} \cdot \mathrm{kg}^{-1}$ a amené une diminution significative mais transitoire de la fréquence cardiaque et de la pression artérielle moyenne avec cette technique anesthésique.

Laryngoscopy and tracheal intubation are often associated with hypertension and tachycardia. ${ }^{1,2}$ Induction of anaesthesia using a rapid-sequence technique may exaggerate this chronotropic and pressor response. Accordingly, a variety of techniques has been advocated for control of these haemodynamic events, including pre-induction bolus administration of intravenous narcotics. Fentanyl, when administered prior to induction of anaesthesia, can attenuate the haemodynamic response to tracheal intubation, ${ }^{3,4}$ but the doses required may result in prolonged respiratory depression following procedures of relatively short duration. 5

Alfentanil, the newest, clinically available, opiate analgesic, has pharmacokinetic and pharmacodynamic properties which are more desirable for a rapid-sequence induction technique. Alfentanil is potent, has a rapid onset of action, ${ }^{6}$ and has the shortest elimination half-life of currently available narcotics. ${ }^{7,8}$ For patients at risk of pulmonary aspiration, the rapid onset and potency of alfentanil should be advantageous during rapid-sequence induction of anaesthesia when this drug is used to modify the cardiovascular response to intubation. Furthermore, because of its short duration of action, a more rapid recovery is possible with alfentanil than with fentanyl, ${ }^{9}$ which is particularly desirable for this patient population.

A randomized, double-blind and placebo-controlled trial was performed in order to determine the efficacy and dose response of alfentanil to attenuate the hyperdynamic cardiovascular response associated with rapid-sequence induction of anaesthesia. A second purpose of the study was to determine the influence of alfentanil on global indices of cardiac function, using a non-invasive thoracic electrical bioimpedance (TEB) cardiac monitor.

\section{Methods}

\section{Patient population}

Sixty ASA physical status I and II patients scheduled for elective surgical procedures under general anaesthesia entered the study. Each patient gave written informed consent to the protocol which was approved by the Hospital Human Experimental Procedures Committee. Excluded were patients greater than $70 \mathrm{yr}$ of age; those with hypertension defined as a systolic BP exceeding $160 \mathrm{mmHg}$ or a diastolic BP exceeding $90 \mathrm{mmHg}$ on three consecutive ward readings; patients who had received any beta-blocking or antihypertensive drug in the two weeks before surgery; and patients with upper airway abnormalities which might prolong the time required for intubation.

\section{Study medication}

Aqueous alfentanil $\mathrm{HCl}$ was prepared on the morning of surgery by the Hospital Pharmacy, in concentrations of 250,375 , and $500 \mu \mathrm{g} \cdot \mathrm{kg}^{-1}$. The study medication was delivered in coded $10 \mathrm{ml}$ vials to prevent group identification. Immediately before induction of anaesthesia, each patient was given $0.12 \mathrm{ml} \cdot \mathrm{kg}^{-1}$ of the study medication according to the randomization schedule:

$$
\begin{aligned}
& \text { Group I = normal saline-Placebo (PLAC) } \\
& \text { Group II }=\text { alfentanil } 30 \mu \mathrm{g} \cdot \mathrm{kg}^{-1} \text { (ALF 30) } \\
& \text { Group III = alfentanil } 45 \mu \mathrm{g} \cdot \mathrm{kg}^{-1} \text { (ALF 45) } \\
& \text { Group IV = alfentanil } 60 \mu \mathrm{g} \cdot \mathrm{kg}^{-1} \text { (ALF 60) }
\end{aligned}
$$

\section{Protocol}

Patients were given premedication with oral diazepam $0.15 \mathrm{mg} \cdot \mathrm{kg}^{-1} 90 \mathrm{~min}$ preoperatively. In the operating room, an 18-gauge intravenous catheter was inserted, and each patient received approximately $10 \mathrm{ml} \cdot \mathrm{kg}^{-1}$ Ringer's Lactate during the pre-induction period. Following baseline measurements, droperidol $0.125 \mathrm{mg}$ and d-tubocurarine $3.0 \mathrm{mg}$ were administered intravenously, followed by preoxygenation with 100 per cent $\mathrm{O}_{2}$ for three minutes. The study medication from the coded syringe was then given over $60 \mathrm{sec}$, immediately followed by thiopentone $4.0 \mathrm{mg} \cdot \mathrm{kg}^{-1} \mathrm{IV}$ and succinylcholine 2.0 $\mathrm{mg} \cdot \mathrm{kg}^{-1} \mathrm{IV}$, each administered over $15 \mathrm{sec}$. Cricoid pressure was applied when the patient lost consciousness and, one minute later, the trachea was intubated under direct laryngoscopy. The correct position of the tracheal tube was verified by auscultation of the chest. Following intubation, the lungs were ventilated mechanically with 66 per cent nitrous oxide and oxygen to maintain the end-tidal $\mathrm{CO}_{2}$ between $30-35 \mathrm{mmHg}$. Neuromuscular blockade was maintained with vecuronium, $0.1 \mathrm{mg} \cdot \mathrm{kg}^{-1}$. No other stimulus, such as patient positioning, was permitted over the next five minutes of measurements, at which time the study protocol was completed. During the period of observation, hypotension was defined as a systolic blood pressure below $90 \mathrm{mmHg}$ or less than 30 per cent of the baseline and was treated with $5.0 \mathrm{mg}$ increments of ephedrine as required to achieve normotension. After completion of the study protocol, anaesthesia was maintained according to the discretion of the attending anaesthetist.

\section{Measurements}

All haemodynamic variables were recorded at a baseline awake (BL), one minute following induction of anaesthesia (IND), and every minute for five minutes following intubation (INT $+1 \ldots$ INT +5 ). Heart rate (HR), systolic (SBP), diastolic (DBP) and mean arterial pressure (MAP) were measured from a Critikon Dinamap 1846SXP vital signs monitor. Stroke volume index (SVI), 
cardiac index $(\mathrm{CI})$ and ejection fraction $(\mathrm{EF})$ were measured non-invasively using the principle of thoracic bioimpedance cardiography with the BoMed NCCOM-3 ${ }^{\circledR}$ cardiac monitor (Irvine, California). The principle of deriving stroke volume from changes in thoracic impedance has previously been described. ${ }^{10}$ In brief, thoracic electrical resistivity, or impedance, varies with changes of blood volume in the descending thoracic aorta, such that stroke volume can be mathematically related to impedance changes. The BoMed NCCOM-3 utilizes an equation to generate an estimate of stroke volume from the product of thoracic volume, ventricular ejection time, and the ratio of maximum rate of impedance change to basal impedance. ${ }^{10}$ Cardiac output is calculated from the product of heart rate and stroke volume. The cardiac output is divided by BSA to derive cardiac index. The cardiac monitor displays these values continuously as the average of 16 successive artefact-free beats, and thus new values are updated several times each minute, depending on the heart rate. Bioimpedance measurement of $\mathrm{CI}$ demonstrates an acceptable level of accuracy in a wide variety of clinical conditions, and also provides good trending capabilities. ${ }^{11,13}$ The ejection fraction is displayed continuously on the bioimpedance monitor, and is derived from an equation using systolic time intervals. This measurement of ejection fraction correlates well with that measured by gated blood pool scan radionuclides. ${ }^{14}$ As all haemodynamic measurements were obtained using noninvasive methods, systematic vascular resistance index (SVRI) was calculated using the standard formula assuming that CVP $=0$.

\section{Statistical analysis}

Repeated measures analysis of variance (ANOVA) was performed to evaluate changes over time for each group, and analysis of covariance (ANOCOVA) was used to test for group-time interactions for each haemodynamic variable. Tukey's test was applied to specify intergroup differences at induction of anaesthesia, and one and five minutes following tracheal intubation. Demographic variables were analyzed by Chi-square analysis. The results are reported as mean \pm standard deviation in the text, figures and table. Statistical significance was assumed when $P<0.05$.

\section{Results}

Sixty patients completed the study protocol, and the demographic variables are presented in the Table. Except for a larger proportion of females in Groups I and IV, all groups were similar with respect to age, height, weight and preoperative blood pressure. Although intubating conditions were not specifically graded, airway instrumentation was easily performed in all patients.
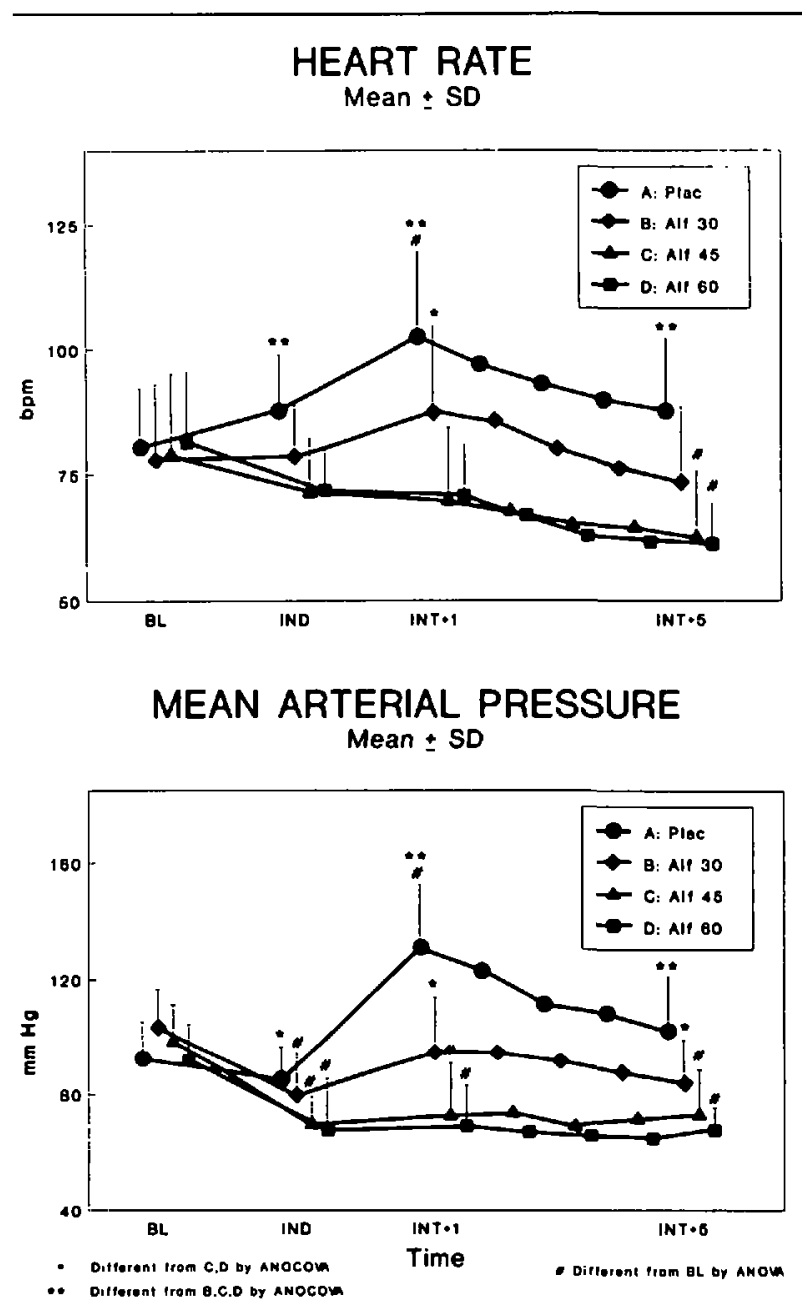

FIGURE 1 Heart rate and mean arterial pressurc during rapid sequence induction (IND) and for the first five minutes following intubation (INT + $1 \ldots$ INT + 5). Changes from baseline are specified by ANOVA and differences between groups by ANOCOVA, with statistical significance assumed when $\mathrm{P}<0.05 . \mathrm{BL}=$ bascline; ALF $30=$ alfentanil $30 \mu \mathrm{g} \cdot \mathrm{kg}^{-1}$, ALF $45=$ alfentanil 45 $\mu \mathrm{g} \cdot \mathrm{kg}^{-1} ; \mathrm{ALF} 60=$ alfentanil $60 \mu \mathrm{g} \cdot \mathrm{kg}^{-1}$.

TABLE Demographic data

\begin{tabular}{lcccc}
\hline & PLAC & ALF 30 & ALF 45 & \multicolumn{1}{l}{ ALF 60 } \\
$n$ & \multicolumn{1}{c}{15} & \multicolumn{1}{c}{15} & \multicolumn{1}{l}{15} & \multicolumn{1}{c}{15} \\
\hline Age (yr) & $43 \pm 11$ & $35 \pm 12$ & $40 \pm 16$ & $39 \pm 14$ \\
Sex (M/F) & $4 / 11$ & $7 / 8$ & $6 / 9$ & $0 / 15$ \\
Height (cm) & $165 \pm 11$ & $168 \pm 11$ & $166 \pm 9$ & $163 \pm 5$ \\
Weight (kg) & $69 \pm 11$ & $76 \pm 12$ & $67 \pm 12$ & $65 \pm 11$ \\
SBP & $116 \pm 14$ & $123 \pm 13$ & $118 \pm 15$ & $114 \pm 12$ \\
DBP & $74 \pm 10$ & $77 \pm 8$ & $71 \pm 10$ & $73 \pm 10$ \\
\hline
\end{tabular}

Demographic variables. SBP = preoperative systolic blood pressure; $\mathrm{DBP}=$ preoperative diastolic blood pressure; $\mathrm{PLAC}=$ placebo, $\mathrm{ALF}$ $30=$ alfentanil $30 \mu \mathrm{g} \cdot \mathrm{kg}^{-1} ;$ ALF $45=$ alfentanil $45 \mu \mathrm{g} \cdot \mathrm{kg}^{-1} ;$ ALF $60=$ alfentanil $60 \mu \mathrm{g} \cdot \mathrm{kg}^{-1}$. 


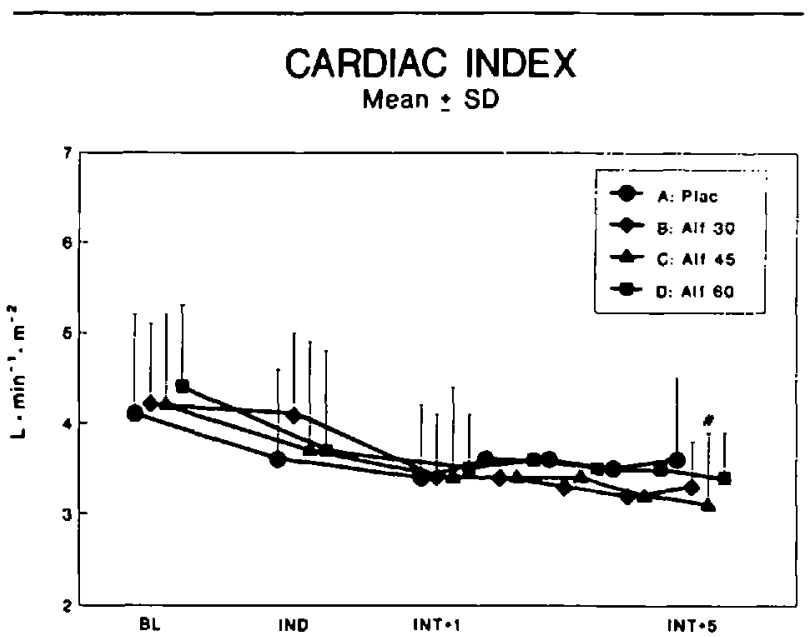

\section{STROKE VOLUME INDEX Mean $\leq$ SD}

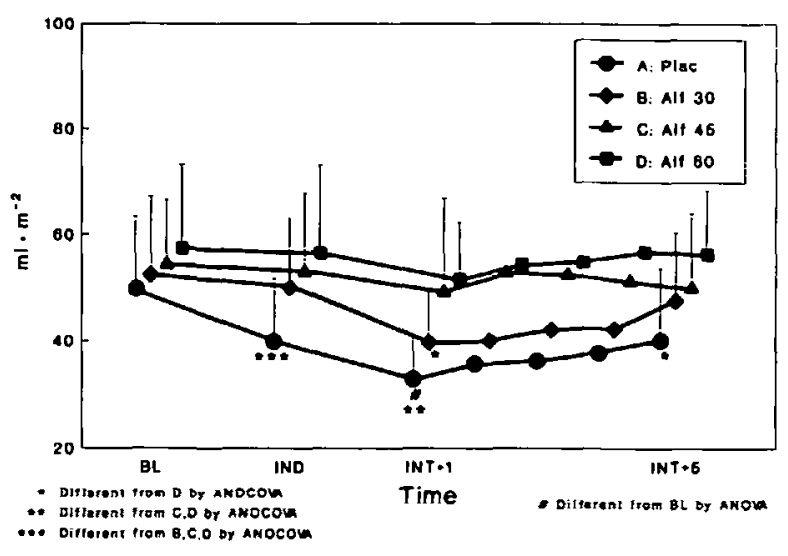

FIGURE 2 Cardiac index (CI) and stroke volume index (SVI) during rapid-sequence induction of anaesthesia and following tracheal intubation. For abbreviations refer to the legend of Figure 1.

\section{Haemodynamic responses}

The heart and blood pressure responses during rapidsequence induction of anaesthesia are presented in Figure 1. Mean heart rate increased by $21 \pm 10 \mathrm{bpm}$ in the first minute post-intubation in the PLAC group, and remained elevated $(P<0.05)$ compared with all three ALF groups following airway instrumentation. In contrast, HR did not change significantly in patients who received ALF 30. Similarly, ALF 45 and ALF 60 also prevented an increase in HR following intubation, but these higher doses of alfentanil were associated with a significant decrease in HR after intubation, compared with respective, awake baseline values.

The MAP responses were similar to the changes in $\mathrm{HR}$. A significant increase in MAP $(28 \pm 13 \mathrm{mmHg})$ occurred in response to intubation in the PLAC group $(P<0.05)$, but there were no significant changes in MAP during

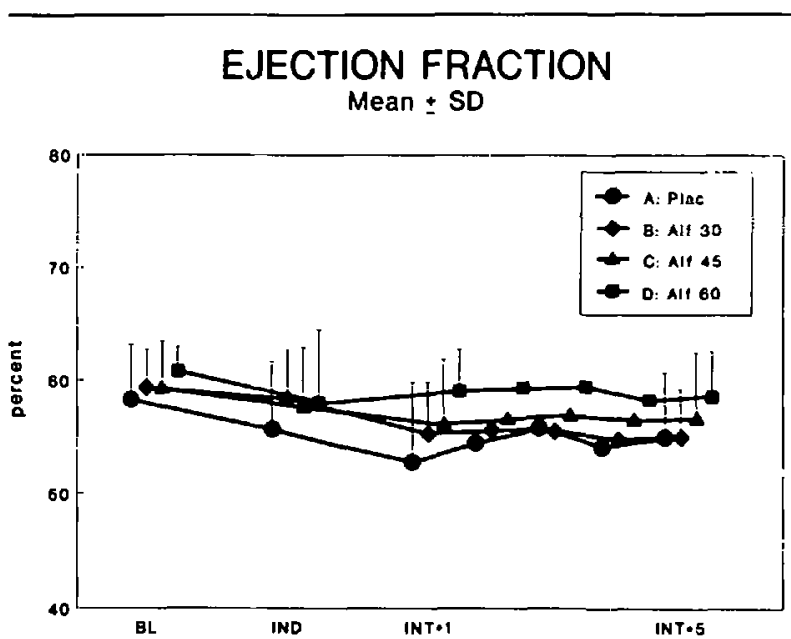

\section{SYSTEMIC VASCULAR RESISTANCE INDEX Mean $\div$ SO}

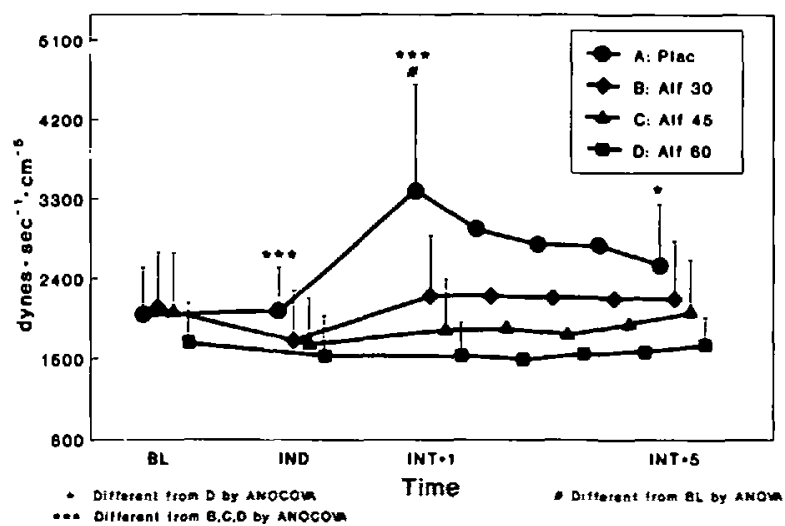

FIGURE 3 Ejection fraction (EF) and systemic vascular resistance index (SVRI) during rapid sequence induction of anaesthesia and following tracheal intubation. For abbreviations refer to the legend of Figure 1 .

induction of anaesthesia and following tracheal intubation after ALF 30. ALF doses of 45 and ALF $60 \mu \mathrm{g} \cdot \mathrm{kg}^{-1}$ resulted in a sustained decrease in MAP after induction $(P<0.05)$, which lasted throughout the study period. One patient in the ALF 45 group, and two patients in the ALF 60 group required treatment with ephedrine.

\section{Cardiodynamic responses}

The effects of rapid sequence induction of anaesthesia and tracheal intubation on cardiac index and stroke volume index are presented in Figure 2. A small, but significant decrease $\left(0.6 \pm 0.4 \mathrm{~L} \cdot \mathrm{min}^{-1} \cdot \mathrm{m}^{-2}\right)$ in mean cardiac index occurred in all four groups in the first minute post-intubation $(P<0.05)$, but there was no further decrease over time. There were also no differences among groups when comparing cardiac index at corresponding times, and 
values remained within the normal range $(2.2-3.8 \mathrm{~L}$. $\min ^{-1} \cdot \mathrm{m}^{2}$ ) throughout the study period. Stroke volume index tended to decrease with time, but again there were no significant differences among groups at any corresponding time during the study period.

Left ventricular ejection fractions, displayed in Figure 3 , were similar at baseline (range $58 \pm 5-62 \pm 3$ per cent) and remained between $54 \pm 7$ and $63 \pm 6$ per cent throughout the study period. There were small variations across time, but no significant group-time interactions were observed. Systemic vascular resistance index, presented in the lower panel of Figure 3, increased markedly by $1420 \pm 780$ dynes $\cdot \mathrm{sec}^{-1} \cdot \mathrm{cm}^{-5}$ in the PLAC group immediately after intubation $(P<0.05)$. In contrast, SVRI remained unchanged when compared to awake baseline values in all three alfentanil groups, during induction and following intubation.

\section{Side effects}

Side effects included clinically significant hypotension, with mean arterial pressure requiring treatment with ephedrine in one patient in the ALF 45 group (six per cent) and $2 / 15$ patients in the ALF 60 group (12 per cent). No patient in the PLAC or ALF 30 groups developed hypotension with MAP less than $70 \mathrm{mmHg}$. No patient developed chest wall rigidity, laryngospasm or bronchospasm.

\section{Discussion}

A proportion of patients undergoing elective or emergency surgical procedures have risk factors for pulmonary aspiration of gastric contents. Safe techniques for general anaesthesia in these patients require that tracheal intubation be performed with rapid sequence induction of anaesthesia. This requirement may exaggerate the hypertensive and tachycardiac response which is frequently associated with routine anaesthetic induction. Several methods have been described for maintaining haemodynamic stability during the induction period, using inhalational anaesthetic agents, beta-adrenergic blocking drugs, intravenous lidocaine, and vasodilators. These agents may be effective, but their use may also result in undesirable side effects, such as hypotension and depression of myocardial contractility. More importantly, use of inhalational or intravenous anaesthetic agents which are slow to reach peak effect, may be inappropriate for patients at risk of bronchoaspiration if the airway is left unprotected for an extended period between the time of loss of consciousness and tracheal intubation.

Opiate analgesics are also efficacious in attenuating the haemodynamic response to intubation. A dose of 5-6 $\mu \mathrm{g} \cdot \mathrm{kg}^{-1}$ of a narcotic such as fentanyl, when given prior to induction with thiopentone, is effective in preventing hypertension and tachycardia secondary to intubation. . $^{3,4}$
However, fentanyl should be administered approximately five minutes prior to induction, in order to allow sufficient time to reach peak analgesic effect before the stimulus of intubation. ${ }^{8}$ Furthermore, this technique may be in appropriate for surgical procedures of short duration, due to relatively prolonged respiratory depression with this dose of fentanyl.

Alfentanil, the newest, clinically available, opiate, has distinct pharmacokinetic and pharmacodynamic properties which make it more suitable for attenuating the haemodynamic response during rapid-sequence induction. Amongst these properties, alfentanil has an extremely rapid onset of action. It has been shown that alfentanil has a half-time of equilibration of $1.1 \pm 0.3$ min between serum narcotic concentration and peak effect within the central nervous system, compared with $6.4 \pm 1.3 \mathrm{~min}$ for fentanyl. ${ }^{6}$ As a result of alfentanil's rapid onset of action, the drug can be administered in bolus fashion immediately prior to induction. A second important property of alfentanil is its rapid termination of effect. Following administration of a single bolus of alfentanil, dissipation of its effect is primarily the result of rapid redistribution from the central to peripheral compartments. ${ }^{7,8}$ Clinically, spontaneous ventilation returns within 15-20 min following a dose of alfentanil of $50 \mu \mathrm{g} \cdot \mathrm{kg}^{-1}$. An equipotent dose of fentanyl, $10 \mu \mathrm{g} \cdot \mathrm{kg}^{-1}$, would render most patients apnoeic for a period of $1-2 \mathrm{hr} .{ }^{6}$ The shorter time to reach the apnoeic threshold, and the shorter recovery time with alfentanil compared with fentanyl, ${ }^{9}$ are potential advantages in patients at risk of aspiration. These advantages would apply not only at induction of anaesthesia, but also upon emergence, in order to facilitate awake extubation with intact airway reflexes following procedures of relatively short duration.

The current study was designed to determine the optimal dose of alfentanil to attenuate the cardiovascular response to laryngoscopy and intubation following rapid-sequence induction. A dose range of $30-60 \mu \mathrm{g} \cdot \mathrm{kg}^{-1}$ was studied, and the alfentanil treatment groups were compared with placebo in order to determine its efficacy. The results demonstrate that all three doses of alfentanil $(30,45$ and $60 \mu \mathrm{g} \cdot \mathrm{kg}^{-1}$ ) were effective in preventing hypertension and tachycardia secondary to intubation in this patient population. However, only alfentanil $30 \mu \mathrm{g} \cdot \cdot \mathrm{kg}^{-1} \mathrm{re}-$ sulted in stability of heart rate and blood pressure throughout the study period. Patients who received higher doses (45 and $60 \mu \mathrm{g} \cdot \mathrm{kg}^{-1}$ ) had small but significant decreases in heart rate, and several patients also became hypotensive. The decrease in mean arterial pressure was clinically important, and required treatment with vasopressor in one patient in the ALF 45 group, two patients in the ALF 60 group, but in no patient who received alfentanil 30 $\mu \mathrm{g} \cdot \mathrm{kg}^{-1}$. 
The control in mean arterial pressure occurred without any significant alteration of systematic vascular resistance index, stroke volume index or ejection fraction in all three alfentanil groups. In contrast, the hypertensive response with placebo produced a significant increase in SVRI and a transient, but significant, decrease in stroke volume index. Although central venous pressure was not measured, it is unlikely that there would have been a greater reduction of preload in the PLAC group compared with any of the three alfentanil groups. Therefore, it is probable that the reduction in SVI with PLAC was attributable primarily to the increase in afterload (SVRI). The reduction in SVI in the placebo group did not further decrease cardiac index when compared with the alfentanil groups, because the tachycardia following intubation compensated for the lower stroke volume index.

Two previous studies have demonstrated that anaesthetic induction with thiopentone is associated with a decrease in left ventricular ejection fraction..$^{15.16} \mathrm{~A}$ direct myocardial depressant effect is the primary mechanism proposed to account for this finding. In contrast, other investigators have shown that induction with unsupplemented high-dose opiate analgesics may actually increase left ventricular ejection fraction. ${ }^{17}$ This may be due to a decrease in afterload (systematic vascular resistance), when myocardial contractility and ventricular preload are relatively unaltered or only minimally depressed. In the current study, pre-induction administration of alfentanil may have preserved left ventricular function during thiopentone induction, as reflected by the relative stability of ejection fraction measurements following administration of the barbiturate. One possible explanation is that alfentanil may decrease afterload sufficiently to compensate for the direct myocardial depressant effect of thiopentone, thereby leaving ejection fraction relatively unchanged.

Finally, critical appraisal of these results must take into consideration possible limitations of assessing cardiac function using the new non-invasive technique of bioimpedance cardiography. Recent studies have validated bioimpedance measurement of cardiac output in different clinical settings, and results have shown good correlation with thermodilution estimates of cardiac output. ${ }^{11-13}$ Despite being the accepted clinical standard of cardiac output determination, the thermodilution technique has a 10-20 per cent range of error, and therefore cannot be considered a true "gold standard." Our group recently completed a study comparing bioimpedance and thermodilution measurements of cardiac output during abdominal aortic surgery. Results showed a good correlation between the two methods of measurement over a range of cardiac outputs. ${ }^{18}$ More importantly, however, bioim- pedance values provided similar trending capabilities when compared with the thermodilution technique. This trending capability is probably more important than absolute accuracy when interventions and measurements are performed serially in the same patients, as in the case of the current study.

This study demonstrated the effectiveness of alfentanil in controlling the haemodynamic response during rapidsequence induction of anaesthesia. Alfentanil doses of 30 , 45 and $60 \mu \mathrm{g} \cdot \mathrm{kg}^{-1}$ prevented hypertension and tachycardia in response to tracheal intubation, while maintaining normal systemic vascular resistance and causing minimal changes in cardiac index and ejection fraction. However, both 45 and $60 \mu \mathrm{g} \cdot \mathrm{kg}^{-1}$ doses of alfentanil may result in hypotension and bradycardia. We conclude that alfentanil $30 \mu \mathrm{g} \cdot \mathrm{kg}^{-1}$ is the optimal dose for ensuring haemodynamic stability, with minimal alteration of cardiac function,during rapid sequence anaesthetic induction with thiopentone. This rapid sequence is simple, safe and effective.

\section{Acknowledgements}

The authors gratefully acknowledge the financial support of Janssen Pharmaceutica, Canada. The authors also wish to thank Dr. Rama Nair for his statistical advice, and the anaesthetists, surgeons and nurses of the operating room at the Ottawa General Hospital, whose assistance and patience permitted these studies.

\section{References}

1 Stoelting $R K$. Circulatory changes during direct laryngoscopy and endotracheal intubation. Anesthesiology 1977; 47: 381-4.

2 Fox EJ, Skiar GS, Hill CH. Complications related to the pressor response to endotrachcal intubation. Anesthesiology 1977; 47: 524-5.

3 Dahlgren $N$, Messeter $K$. Treatment of stress response to laryngoscopy and intubation with fentanyl. Anaesthesia 1981; 36: 1022-6.

4 Martin DE, Rosenburg H, Aukburg SJ et al. Low dosc fentanyl blunts circulatory responses to tracheal intubation. Anesth Analg 1982; 61: 680-4.

$5 \mathrm{MCClain} D A, \mathrm{Hug} C \mathrm{CJ}$. Intravenous fentanyl kinetics. Clin Pharm Ther 1980; 28: 106-14.

6 Scott JC, Ponganis KV, Stanski DR. EEG quantitation of narcotic effect: the comparative pharmacodynamics of fentanyl and alfentanil. Anesthesiology 1985; 62: 234-41.

7 Bovill JG, Sebel PS, Blackburn CL, Heykants $J$. The pharmacokinetics of alfentanil (R30209): a new opioid analgesic. Anesthesiology 1982; 57: 439-43.

8 Camu F, Gepts E, Rucquoi M, Heykants J. Pharmacokinetics of alfentanil in man. Anesth Analg 1982;63: 710-1. 
9 White PF, Coe V, Shafer A, Sung ML. Comparison of alfentanil with fentanyl for outpatient anesthesia. Anesthesiology 1986; 64: 99-106.

10 Bernstein DP. Continuous non-invasive rcal time monitoring of stroke volume and cardiac output by thoracic electrical bioimpedance. Crit Care Med 1986; 14: 898901.

11 Shoemaker W, Appel P, Kram H. Multicomponent noninvasive physiologic monitoring of circulatory function. Crit Care Med 1988; 16: 482-7.

12 Gotshall $R$, Wood V, Miles D. Comparison of two impedance cardiographic techniques measuring cardiac output in critically ill patients. Crit Care Med 1989;17: 806-11.

13 Appel P, Shoemaker W, Kram H, Macabee J, Fleming A. Comparison of cardiac output measurement by noninvasive electrical bioimpedance with thermodilution in critically ill patients. Crit Care Med 1986; 14: 933-5.

14 Capan L, Bernstein D, Patel K, Sanger J, Turndorf H. Measurement of ejection fraction by bioimpedance method. Crit Care Med 1987; 15: 402-5.

15 Giles RW, Berger HJ, Barash $P G$. Continuous monitoring of left ventricular performance with computerised nuclear probe during laryngoscopy and intubation before coronary artery bypass surgery. Am J Cardiol 1982, 50: 735-41.

16 Chraemmer-Jorgensen B., Hoilund-Carlseon PF, Marving $J$, Pederson $J F$. Left ventricular performance monitored by radionuclide cardiography during induction of anesthesia. Anesthesiology 1985; 62: 278-86.

17 Miller DR, Wellwood M, Teasdale SJ et al. Effects of anaesthetic induction on myocardial function and metabolism: a comparison of fentanyl, sufentanil and alfentanil. Can J Anaesth 1988; 35: 219-33.

18 Sullivan PJ, Martineau RJ, Hull KA, Miller DR. Comparison of bioimpedance and thermodilution measurements of cardiac output during abdominal aortic surgery. Can J Anaesth 1990; 37: S78. 